Bull. Mater. Sci., Vol. 6, No. 1, February 1984, pp. 83-89.

(C) Printed in India.

\title{
Effect of compositional modifications on the piezoelectric properties of spray dried lead zirconate titanate ceramics
}

\author{
RAMJI LAL and P RAMAKRISHNAN \\ Department of Metallurgical Engineering, Indian Institute of Technology, Bombay 400076 , \\ India
}

\begin{abstract}
Lead zirconate titanate powders of different compositions varying from 50 to 55 atomic percent zirconium in the solid solution have been prepared by spray-drying technique. The compositions were varied by changing the zirconium-to-titanium ratio in the solid solution and also with the addition of strontium. The amorphous character of the as-prepared powders and the formation of single phase lead zirconate titanate during calcination were also confirmed by $x$-ray diffraction technique. These powders were then converted to piezoelectric ceramics by compaction and sintering followed by electroding and poling. Effect of the variation of zirconium to titanium ratio and strontium additions on the piezoelectric properties of the finished ceramics have been explained on the basis of improved sintering, uniform grain size, formation of morphotropic phase boundary and subsequent shift to rhombohedral structure.
\end{abstract}

Keywords. Lead zirconate titanate; piezoelectricity; ceramic materials; spray drying; sintering; amorphous character; morphotropic phase boundary.

\section{Introduction}

Lead zirconate titanate, $\mathrm{Pb}(\mathrm{Zr}, \mathrm{Ti}) \mathrm{O}_{3}$, solid solution system exhibits piezoelectric properties when it is converted into the form of ceramics and subjected to high d.c. electric field. Piezoelectric properties of the system are considerably influenced by varying $\mathrm{Zr}$ to $\mathrm{Ti}$ ratio in the solid solution and acquires maximum value when the ratio corresponds to morphotropic phase boundary composition. However this ratio has been found to have different values from the reported literature of various investigators (Webster et al 1965; Ikeda et al 1962; Jaffe et al 1954, 1955). These variations can be attributed to the difference in the purity, reactivity and homogeneity of the raw materials as well as the nature of calcined lead zirconate titanate (LZT) powders. Majority of these investigators have used the conventional ceramic processing techniques where the process parameters are essentially based on tedious trial-anderror methods. Besides, the starting particle size distribution of powders prepared by conventional processing are non-reproducible and the phase always has a degree of spatial inhomogeneity. The optimum $\mathrm{Zr}$ to $\mathrm{Ti}$ ratio for the appearance of phase boundary in the solid solution depends upon the method of powder preparation and ceramic processing parameters. Ceramic powders prepared by chemical methods are, therefore, gaining more importance because of their improved homogeneity and reactivity and hence capable of producing decisive morphotropic phase boundary at a particular Zr-to-Ti ratio. Several investigators (Murata and Wakino 1976; Heartling and Land 1972; Mc Namara 1965; de Lau 1970; John Thomson 1974; Ramji Lal and Ramakrishnan 1979, 1980) have reported using chemical processing such as spraydrying, freeze-drying and chemical coprecipitation to prepare electronic ceramics with encouraging results. 
The objective of this work is, therefore, to locate the phase boundary composition in LZT ceramics when prepared by spray-dried powders and also to arrive at the best composition in the entire solid solution series. It is also intended to substitute a small quantity of $\mathrm{Pb}$ with $\mathrm{Sr}$ in solid solution to improve certain important electromechanical properties of the ceramics by optimising strontium concentration.

\section{Experimental procedure}

Lead zirconate titanate ceramic powders were prepared by spray-drying technique in 6 batches with $\mathrm{Zr}$ to $\mathrm{Ti}$ ratio varying from $50: 50$ to 55:45 in the stoichiometric formula $\mathrm{Pb}\left(\mathrm{Zr}_{x} \mathrm{Ti}_{1-x}\right) \mathrm{O}_{3}$. Lead nitrate, zirconium oxychloride and titanium tetrachloride were used as starting raw materials which were further purified by crystallization and precipitation. These were converted to nitrate solutions and then mixed in the desired proportions for spray drying. A laboratory model spray drier with the following parameters were used for preparing the powders: spray rate of $3 \mathrm{l} / \mathrm{hr}$, speed of centrifugal atomizer 30000 r.p.m., inlet temperature $320-350^{\circ} \mathrm{C}$, outlet temperature $90-110^{\circ} \mathrm{C}$, solution $\mathrm{pH} 1.8$ and solid content $50 \mathrm{~g} /$ litre. The desired characteristics of the powders were confirmed by $\mathrm{x}$-ray diffraction analysis and obtained through the control of calcination parameters. The $\mathrm{x}$-ray diffraction pattern of the powders is shown in figure 1.

Powders of different compositions were calcined at $550^{\circ} \mathrm{C}$ for $4 \mathrm{hr}, 650^{\circ} \mathrm{C}$ for $2 \mathrm{hr}$ and finally at $750^{\circ} \mathrm{C}$ for $2 \mathrm{hr}$ which provided the powders of desired characteristics. Chemical analysis of the calcined powders indicated the presence of unreacted $\mathrm{PbO}$ varying between 1.5 to $2 \%$. Powders were then compacted into circular discs of

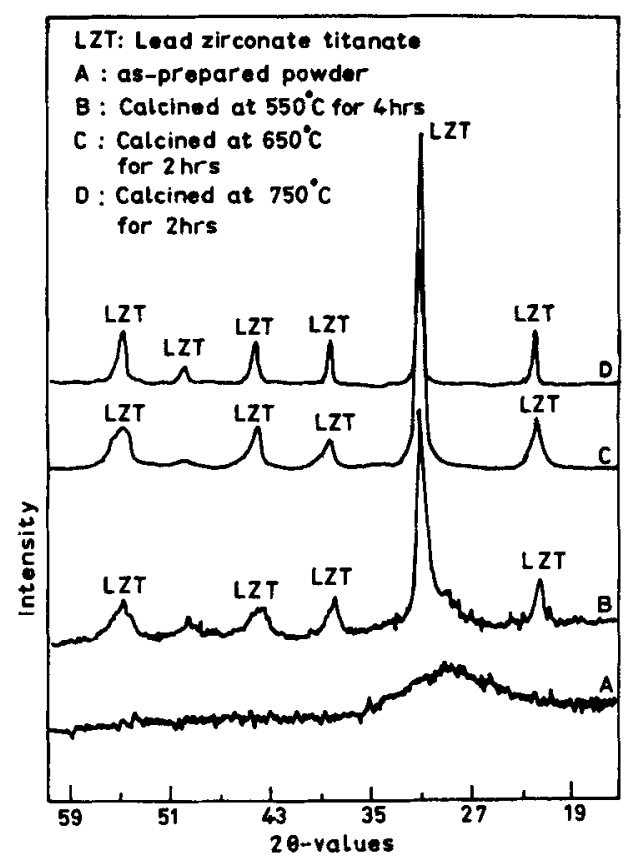

Figure 1. X-ray diffraction pattern of as-prepared powders. 
diameter $24 \mathrm{~mm}$ and thickness $2 \mathrm{~mm}$ by using about $1.5 \mathrm{wt} \% \mathrm{PVA}$ as binder. These discs were sintered at $1250^{\circ} \mathrm{C}$ for $2 \mathrm{hr}$ under $\mathrm{PbO}$ atmosphere to suppress the lead volatility from the specimens. Sintered discs were lapped to make the surfaces flat and parallel and then electroded by applying silver paste. Electroded ceramics were poled by applying a d.c. electric field of $30 \mathrm{kV} / \mathrm{cm}$ at $100^{\circ} \mathrm{C}$ in silicone oil bath for 15 minutes and piezoelectric properties were measured. Properties of ceramics as a function of composition are shown in figure 2 .

Separate batches of composite solutions were also prepared by replacing 3, 6 and 9 at . \% of $\mathrm{Pb}$ with $\mathrm{Sr}$ in the stoichiometric compositions and powders were prepared by following similar technique as described earlier for unmodified compositions and processed into the form of finished ceramics. Piezoelectric properties of the ceramics were measured and reported in table 1. Properties of one batch of ceramics containing 6 at . \% Sr have also been plotted as a function of the variation of $\mathrm{Zr}$ to $\mathrm{Ti}$ ratio and shown in figure 3. In another batch of decomposed powders containing 6 at $\cdot \% \mathrm{Sr}$ substituted for $\mathrm{Pb} ; 2 \mathrm{wt} \%$ of $\mathrm{PbO}$ was added in excess and then the powders were calcined and processed by similar processing parameters. Properties of these ceramics are reported in table 2. Compositions with and without $\mathrm{Sr}$ were analysed by $\mathrm{x}$-ray diffraction technique using $\mathrm{CuK}_{\alpha}$ radiation to correlate the change in unit cell parameters with the average volume of the substituted ions. X-ray diffraction results of the compositions are shown in table 3. In order to correlate the microstructures, investigations of the sintered ceramics with and without $\mathrm{Sr}$ have also been carried out. A few typical photomicrographs of the sintered ceramics are shown in figures $4(a)$ and $4(b)$.

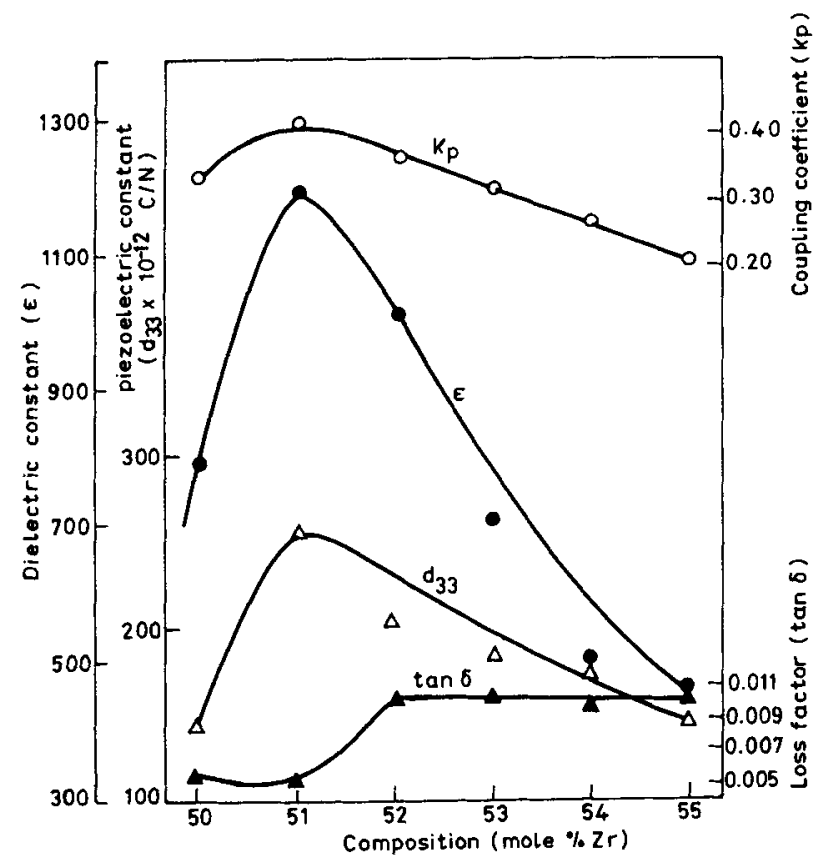

Figure 2. Variation of properties with compositions of unmodified LZT ceramics. 
Table 1. Effect of $\mathrm{Sr}$ concentration on properties of $\mathrm{LZT}$ ceramics

\begin{tabular}{|c|c|c|c|c|c|}
\hline \multirow{2}{*}{$\frac{\text { Composition }}{\mathrm{Zr}: \mathrm{Ti}+\mathrm{Sr} .}$} & \multicolumn{5}{|c|}{ Properties } \\
\hline & $\rho$ & $\varepsilon$ & $\operatorname{Tan} \delta$ & $d_{33}\left(\times 10^{-12} \mathrm{C} / \mathrm{N}\right)$ & $K_{\text {p }}$ \\
\hline $51: 49+3$ & $7 \cdot 20$ & 862 & 0.0075 & 155 & 0.32 \\
\hline $52: 48+3$ & $7 \cdot 20$ & 911 & 0.0070 & 170 & 0.37 \\
\hline $53: 47+3$ & $7 \cdot 20$ & 798 & 0.0090 & 153 & 0.35 \\
\hline $54: 46+3$ & $7 \cdot 20$ & 760 & 0.0096 & 140 & 0.32 \\
\hline $51: 49+6$ & $7 \cdot 41$ & 886 & 0.0071 & 173 & 0.41 \\
\hline $52: 48+6$ & $7 \cdot 44$ & 1050 & 0.0055 & 216 & 0.48 \\
\hline $53: 47+6$ & $7 \cdot 49$ & 1532 & 0.0045 & 295 & 0.56 \\
\hline $54: 46+6$ & $7 \cdot 48$ & 736 & $0-0075$ & 150 & 0.42 \\
\hline $51: 49+9$ & $7 \cdot 30$ & 550 & 0.0120 & 121 & 0.32 \\
\hline $52: 48+9$ & $7 \cdot 30$ & 560 & 0.0085 & 152 & 0.37 \\
\hline $53: 47+9$ & $7 \cdot 30$ & 540 & 0.0092 & 141 & 0.35 \\
\hline $54: 46+9$ & $7 \cdot 33$ & 530 & 0.0120 & 139 & 0.31 \\
\hline
\end{tabular}

$\rho$ : density; $\varepsilon:$ dielectric constant; $\tan \delta$ : dielectric loss; $d_{33}:$ piezoelectric constant; $K_{p}$ : electromechanical coupling coefficient.

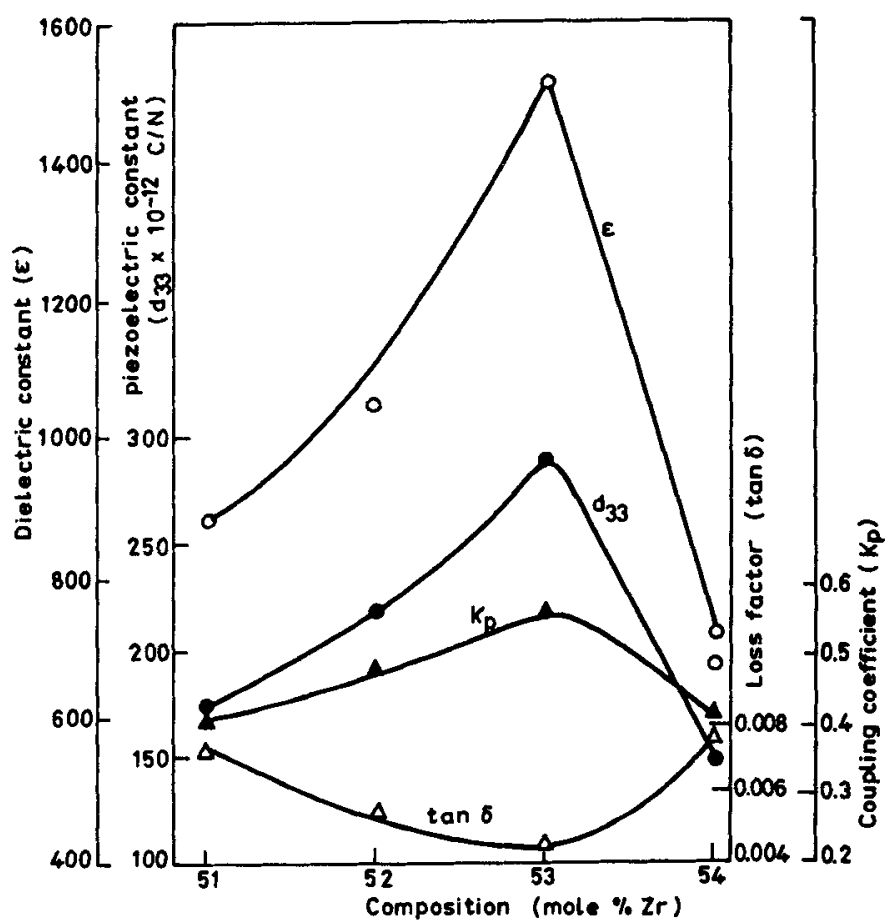

Figure 3. Variation of properties with composition of $\mathrm{Sr}$ modified LzT ceramics. 
Table 2. Effect of excess PbO on properties of Sr modified LzT ceramics

\begin{tabular}{|c|c|c|c|c|c|}
\hline \multirow{2}{*}{ 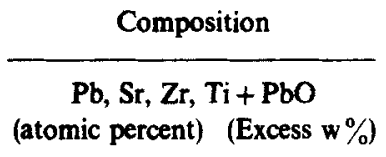 } & \multicolumn{5}{|c|}{ Properties } \\
\hline & $\rho$ & $\varepsilon$ & $\tan \delta$ & $d_{33}\left(\times 10^{-12} \mathrm{C} / \mathrm{N}\right)$ & $K_{p}$ \\
\hline $94,6,51,49+2$ & 7.59 & 1098 & 0.0039 & 223 & 0.45 \\
\hline $94,6,52,48+2$ & 7.57 & 1027 & 0.0054 & 214 & 0.435 \\
\hline $94,6,53,47+2$ & 7.59 & 921 & 0.0180 & 193 & 0.39 \\
\hline $94,6,54,46+2$ & 7.59 & 890 & 0.0195 & 180 & 0.32 \\
\hline
\end{tabular}

Notation of symbols same as in table 1.

Table 3. X-ray diffraction results of LzT composition

\begin{tabular}{lllllllll}
\hline Composition & \multicolumn{10}{c}{$2 \theta$ values } \\
\hline $\mathrm{Pb}_{1.0}\left(\mathrm{Zr}_{0.51} \mathrm{Ti}_{0.49}\right) \mathrm{O}_{3}$ & 21.7 & 31 & 38.2 & 44.2 & 49.8 & 55 & 64.6 & 73 \\
$\mathrm{~Pb}_{0.94} \mathrm{Sr}_{0.06}\left(\mathrm{Zr}_{0.53} \mathrm{Ti}_{0.47}\right) \mathrm{O}_{3}$ & 21.9 & 31 & 38.3 & 44.8 & 50.4 & 55.4 & 64.8 & 74 \\
\hline
\end{tabular}

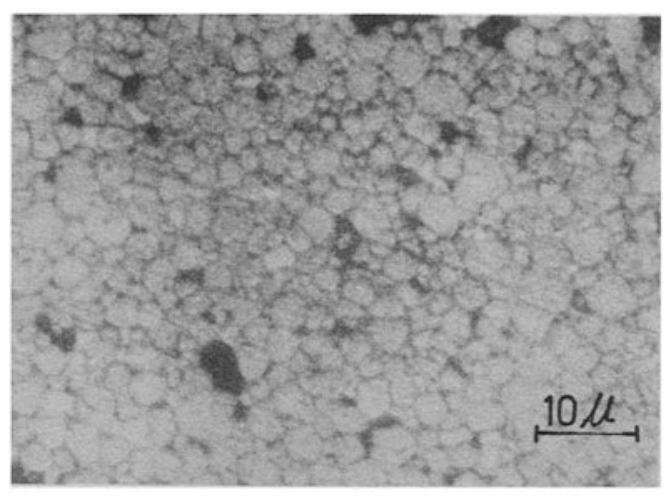

(a)

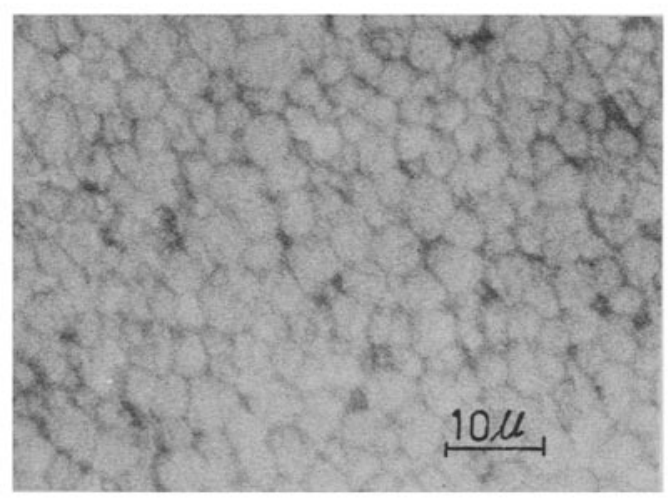

(b)

Figure 4. Photomicrographs of sintered LZT ceramics, a. unmodified. b. Sr-modified. 


\section{Results and discussion}

Spray-dried powders have been found to possess amorphous characteristics according to the $\mathrm{x}$-ray diffraction pattern shown in figure 1 . Further the formation of single phase LZT at lower calcining temperatures and the absence of second phase indicate higher reactivity, homogeneity and purity of these powders in relation to conventional processed powders. From the analysis of the piezoelectric properties of LZT compositions shown in figure 2 , it appears that dielectric constant $(\varepsilon)$, piezoelectric constant $\left(d_{33}\right)$ and electromechanical coupling coefficient $\left(k_{p}\right)$ acquire maximum value at a particular $\mathrm{Zr}$-to-Ti ratio whereas dissipation factor $(\tan \delta)$ is the minimum at this ratio. Thus it is confirmed that in LzT solid solution system, there exists a phase boundary composition having maximum dielectric, piezoelectric and coupling coefficient and minimum dissipation factor in the entire series. This composition corresponds to approximately $51: 49 \mathrm{Zr}$ to $\mathrm{Ti}$ ratio. Thus the appearance of phase boundary takes place at a lower ratio of $\mathrm{Zr}$ to $\mathrm{Ti}$ in composition prepared by spray-dried powders than those prepared from conventional processed powders. This can be attributed to the greater reactivity of spray-dried powders as indicated by the amorphous character from the $x$ ray diffraction pattern in figure 1 . The higher reactivity of spray-dried powders enables more zirconium to react and enter into solid solution and thus achieving the required stoichiometry with starting composition having lower $\mathrm{Zr}$-to-Ti ratio.

A similar trend in properties has also been observed with $\mathrm{Sr}$ substituted compositions but the phase boundary has been shifted towards rhombohedral side (i.e. from $\mathrm{Zr}$ to $\mathrm{Ti}$ ratio of 51:49 to 53:47). This shift in the phase boundary composition is in accordance with the phase diagram of $\mathrm{PbZrO}_{3}-\mathrm{PbTiO}_{3}-\mathrm{SrTiO}_{3}-\mathrm{SrZrO}_{3}$ reported by Ikeda (1959). It is also observed that $\mathrm{Sr}$ increases the dielectric and piezoelectric constants as well as electromechanical coupling factor and also lowers the dissipation factor when added in A-site in phase boundary composition. This trend increases up to 6 at.$\% \mathrm{Sr}$ and then decreases when $\mathrm{Sr}$ content increases from 6 at $\%$ (table 2). This variation can be explained on the basis of higher sintering rate of $\mathrm{Sr}$ due to its greater diffusion characteristics caused by lattice defects (size of $\mathrm{Sr}$ being smaller than $\mathrm{Pb}$ ). Thus $\mathrm{Sr}$ acts as a fluxing agent up to a certain concentration. This results in a pore-free grain structure as seen in figures 4(a) and 4(b). Since pore-free grains have fewer mechanisms for dielectric loss, this reduces the value of $\tan \delta$. Better densification and larger grains of ceramics with $\mathrm{Sr}$ substitution can be considered as reasons for higher dielectric constant. A comparison of the microstructure of LZT ceramics with and without $\mathrm{Sr}$ as shown in figures 4(a) and 4(b) also supports the above argument. Increase of piezoelectric constant in strontium-added ceramics can be explained on the basis of the weakening of dipole-dipole interaction. From the $2 \theta$ values of the different compositions obtained from $x$-ray diffraction and shown in table 3 , it can be concluded that $\mathrm{Sr}$ addition reduces the unit cell volume of the perovskite structure which is expected due to the smaller size of $\mathrm{Sr}^{2+}$ as compared to $\mathrm{Pb}^{2+}$. A comparison of the properties of the compositions containing excess $\mathrm{PbO}$ with original compositions (tables 1 and 2) clearly indicates that addition of excess of $\mathrm{PbO}$ increases the density of the ceramics and also shifts the morphotropic phase boundary towards lower atomic ratio of $\mathrm{Zr}$ to $\mathrm{Ti}$. This shift can be explained from the principle that excess $\mathrm{PbO}$ enables more zirconium to enter in the solid solution as $\mathrm{PbZrO}_{3}$ and thus increases the $\mathrm{Zr}$ ratio. These data also confirm the shift in the phase boundary reported earlier while discussing the results of Sr substituted compositions. Lower value of $\tan \delta$ can be attributed to the better 
stoichiometry of the composition. This is also apparant from the gradual increase in $\tan \delta$ values of the compositions (table 1) when $\mathrm{Zr}$ to Ti ratio varies from 53:47 to 51:49 in the solid solution.

\section{Conclusions}

Lead zirconate titanate powders prepared by spray-drying technique have been found to be amorphous and the formation of single LzT phase is possible at lower calcining temperatures compared to conventionally prepared powders. Piezoelectric properties of the finished ceramics are considerably influenced by the variation of $\mathrm{Zr}$-to-Ti ratio and the values of the properties are optimised at 51 at $\% \mathrm{Zr}$ in the stoichiometric formula of $\mathrm{Pb}\left(\mathrm{Zr}_{x} \mathrm{Ti}_{1-x}\right) \mathrm{O}_{3}$. The relatively lower ratio of $\mathrm{Zr}$ to $\mathrm{Ti}$ providing optimum properties may be attributed to the higher reactivity, better homogeneity and purity of these powders. Strontium addition to lead zirconate titanate acts as a fluxing agent and thus enhances the sinterability of the powders resulting in improved densification and uniform grain size formation. Sr substitution $(6 \mathrm{at} \cdot \%)$ for $\mathrm{Pb}$ reduces the unit cell volume, shifts the morphotropic phase boundary towards rhombohedral symmetry of the phase diagram and provides optimum piezoelectric properties.

\section{References}

de Lau J G M 1970 Am. Ceram. Soc. Bull. 49572

Heartling G H and Land C E 1972 IEEE Trans. Sonic Ultrasonic SU19 269

Ikeda T 1959 J. Phys. Soc. Jpn 141286

Ikeda T, Okano T and Watnabe M 1962 Jpn. J. Appl. Phys. 1218

Jaffe B, Roth R S and Marzullo S 1954 J. Appl. Phys. 25809

Jaffe B, Roth R S and Marzullo S 1955 J. Res. Nat. Bur. Stds. 55239

John Thomson J R 1974 Am. Ceram. Soc. Bull. 53421

McNamara 1965 J. Can. Ceram. Soc. 34103

Murata M and Wakino K 1976 Mater. Res. Bull. 11323

Ramji Lal and Ramakrishnan P 1979 Trans. Indian Ceram. Soc. 38166

Ramji Lal and Ramakrishnan P 1980 in Fine particle processing (ed). P Somasundaram (New York: Am. Inst. Mining Met. Petrol. Engineers) Vol. 1, p 15.

Webster A H, Mc Donald and Bowman W S 1965 J. Can. Ceram. Soc. 3497 